\title{
Contribuições de produções acadêmicas nacionais sobre Química Verde e seu ensino
}

Contributions of Brazilian academic productions on Green Chemistry and its teaching

Franciani Becker Roloff ${ }^{1}$

Carlos Alberto Marques ${ }^{2}$

\section{Resumo}

O presente trabalho é parte de uma pesquisa relativa a circulação de ideias sobre Química Verde (QV) contidas em produções científicas nacionais autodenominadas em QV, especificamente aquelas publicadas nas revistas e encontros anuais da SBQ, entre 2002 e 2014. Aqui reportamos um estudo que identificou e analisou trabalhos que continham resultados de pesquisa, relatos de experiências e textos de disseminação relacionados ao ensino da QV. A classificação foi quanto ao foco principal de cada trabalho, se voltado a conteúdos disciplinares ou ao currículo (formação do químico e/ou do professor), buscando-se por características do problema que originou cada trabalho e sua associação à QV. Percebeu-se uma predominância de propostas que vinculam a QV à Química Ambiental e ao Desenvolvimento Sustentável, sua associação com atividades experimentais e que a circulação destas produções vem influenciando proposições voltadas ao ensino da QV para todo o campo da Química.

Palavras chave: ensino da QV; circulação de ideias; publicações SBQ; formação de professores de Química.

\section{Abstract}

This work is part of a research of circulation of ideas about Green Chemistry (GC) contained in national scientific productions, self - described in GC, published in the journals and annual meetings of the SBQ between 2002 and 2014. We reported a study that identified and analyzed works containing research results, reports of experiences and dissemination texts related to the teaching of GC. The classification was based on the main focus of each work related to disciplinary contents or curriculum (chemistry teacher training and/or teacher), searching for the problem characteristics that originated each work and its association with GC. It was noticed a predominance of proposals that link GC to Environmental Chemistry and Sustainable Development, its association with experimental activities and the circulation of these productions which has been influencing propositions related to the teaching of GC at the entire field of Chemistry.

Keywords: Green Chemistry teaching; circulation of ideas; SBQ publications; chemistry teacher training.

\footnotetext{
${ }^{1}$ Universidade Federal de Santa Catarina | franroloff@gmail.com

${ }^{2}$ Universidade Federal de Santa Catarina | bebeto@ced.ufsc.br
} 


\section{Introdução}

O crescente compromisso da Química com a prevenção de danos ambientais tem sido possível em grande parte pelas contribuições de um novo campo de estudos denominado Química Verde (QV). Esse campo envolve várias áreas de pesquisas acadêmicas e também da indústria química - implicando inclusive em várias atividades econômicas (Ritter, 2001) cujos resultados apontam uma evolução na postura e na abordagem de processos de síntese e de produtos deles derivados, por meio do design de moléculas mais benignas (menor toxicidade) e na eliminação e redução da poluição. Compreender se essas mudanças de postura sinalizam um novo modo de pensar e praticar a Química, pode ajudar a reforçar seus compromissos na busca pela sustentabilidade ambiental (SA).

Em 2016 a QV comemorou 25 anos e desde sua emersão, marcada pelo Pollution Prevention ACT (USA, 1990), com a publicação dos seus 12 Princípios (Anastas; Warner, 1998), que tornou esse campo inovador mais conhecido no mundo. Desde o início, inúmeros são os químicos que têm aderido às suas temáticas de investigação, aumentando significativamente o volume de artigos publicados e em circulação, em vários periódicos internacionais e nacionais. Um bom exemplo são as revistas da Sociedade Brasileira de Química - SBQ (Souza-Aguiar et al., 2014; Zuin et al., 2015). Por outro lado, se cresce a produção em QV, também há certa timidez em estudos e relatos de experiências ligadas ao seu ensino e há pequena presença nos currículos de formação dos químicos (Zuin, Marques, 2014; Roloff, 2016; Sandri; Santin-Filho, 2016). Aspecto que pode estar indicando que a circulação dessas produções ainda não tem auxiliado em modificações e/ou em incorporações no ensino da química.

Consideramos, então, relevante realizar um levantamento de produções científicas contendo propostas e relatos de experiências ligadas ao ensino da QV, para melhor compreender a dinâmica de construção, disseminação e, especialmente, da circulação coletiva dos conhecimentos (ideias e práticas) (Fleck, 2010) desse novo campo da Química. Visamos contribuir com a comunidade de educadores químicos no desenvolvimento do ensino da QV e de mudanças no currículo nessa perspectiva. Para tanto, fomos buscar publicações em revistas da SBQ e anais de suas reuniões anuais (RASBQ).

Estruturamos esse artigo situando inicialmente aspectos da Química no contexto da crise ambiental. Em seguida, destacamos respostas que o campo da QV vem dando ao seu enfrentamento. Na terceira seção, disserta-se sobre a importância da difusão e circulação das produções científicas QV à evolução da Química, pelo qual situamos a base epistemológica da discussão, apoiados na categoria circulação de conhecimentos, de Ludwik Fleck. Segue-se com a metodologia onde se apresentam os dados coletados, a análise e a discussão sobre o panorama amostral. Por último, se apresentam as considerações finais.

\section{A química no contexto da crise ambiental}

Desde a publicação do Relatório Brundtland (CMMA, 1991) a indústria química, especialmente por meio da ecologia industrial (Graedel; Allenby, 1995; Machado, 2011), vem buscando aprimorar sua performance tecnológica, com novos e melhores processos e produtos, para uma sociedade e mercado cada vez mais exigente em relação ao ambiente (Marion et al.,2017; Ritter, 2001). Vários são os setores e segmentos sociais que têm 
empregado a chamada "pegada ecológica" (Rees, 1992) como quesito de transparência envolvendo a produção e o consumo de bens; o que no caso da química (Marion et al.,2017) implica o acompanhamento das várias etapas do produto químico, desde seu fabrico até o fim do seu ciclo de vida no ambiente natural. Nesse último quesito, quando se parametriza pelos princípios da QV, essa mostra todo seu potencial como ciência da sustentabilidade (Scott; Lee, 2016). Tais avanços, contudo, demandam muita pesquisa e inovação, com forte aporte científico do meio acadêmico.

É bom lembrar que a Química é uma ciência cujas atividades implicam conhecer e manipular as propriedades dos materiais para se promover transformações/reações visando formar (novas) substâncias, fornecendo insumos e produtos necessários a nós todos. Mas grande parte desses processos inevitavelmente geram resíduos (materiais e energéticos) indesejáveis e poluentes. Infelizmente, a prática da química tradicional tem tido pouca atenção com destino final desses poluentes, muitos destes indo diretamente parar na atmosfera, no solo e na água, contaminando ecossistemas e atingindo as diferentes formas de vida. Os efeitos entrópicos danosos ao ambiente natural e humano (Mozeto; Jardim, 2002), se fazem sentir na chamada crise ambiental.

Há cada vez mais consenso de que a crise ambiental produz externalidades, a exemplo do aquecimento global, que ameaça e põe em risco a sobrevivência das espécies e o futuro da humanidade (IPCC, 2000). Nascimento (2012) aponta quatro versões a essas ameaças: I) o comprometimento da manutenção do planeta Terra; II) obstáculo à existência da vida em geral; III) extinção do ser humano; IV) a degradação das condições de vida humana; vertente essa que incorpora as variáveis socioeconômicas e ambientais. Considera que as crises, ambiental (pouco compreendida) e econômica, resultam de ações antrópicas com fontes difusas, mas com resultados globais, e para enfrentá-las, três proposições são sugeridas: a primeira advoga uma maior eficiência tecnológica, mediante a utilização de menos recursos naturais e energia. Na segunda vertente, mais hegemônica na atualidade, abraça a definição-conceito de desenvolvimento sustentável (DS) (WCED, 1987), cuja ideia é de que o uso racional e parcimonioso dos recursos naturais garantirá o desenvolvimento sem comprometer as necessidades das gerações futuras. A terceira considera que o atual modelo de desenvolvimento nos levará à autodestruição, sendo necessário um decrescimento econômico (Georgescu-Roegen, 2012), tese que considera que "o processo econômico, do ponto de vista puramente físico, não faz mais do que transformar recursos naturais de valor (baixa entropia) em resíduos (alta entropia)" (p. 62).

Estando a Química envolvida em boa parte da crise ambiental - origem, natureza, efeitos e soluções -, sua reação proativa tem se fundamentado e está na base da QV. Mas a complexidade da química exige muita pesquisa e inovações, especialmente no campo do design para o alcance da benignidade de moléculas e de processos mais limpos para a degradação de compostos ao final de seu uso. Algo que exige uma mudança de mentalidade, agora dirigida à sustentabilidade, fazendo evoluir a prática da química tradicional para uma química verde. Implica também compromissos éticos (Browner, 1993) com os princípios da prevenção e da precaução (Barbosa, et al. 2016). Elementos que trazem desafios e complicações ao estilo de pensamento (EP) vigente (Fleck, 2010), de modo que mapear e analisar as produções em QV, sua disseminação e penetração na comunidade química, pode contribuir ao enfrentamento e resolução das eventuais complicações nos processos de ensino e formação dos químicos. 


\section{Contribuições da QV à formação de novas práticas químicas e ao seu ensino}

Os efeitos da emersão da QV se fizeram sentir em toda a Química, em nível internacional e também no Brasil (Zuin, 2013; Souza-Aguiar et al.; 2014). Segundo Epicoco e colaboradores (2014), a adoção de seus princípios pelas áreas da Química conduziu a conformação de uma Comunidade Epistemológica em torno da QV (CE-QV), constituída por uma rede de profissionais que compartilham, dentre outros, desses princípios e de um conjunto de crenças normativas, em uma racionalidade baseada em valores para a ação social dos seus membros. Os empreendimentos da QV, então, orientam pesquisas e inovações que são difundidas na literatura da área, fornecendo ideia e resultados, num sistema de compartilhamento envolvendo a comunidade de químicos.

Alguns trabalhos na literatura têm oferecido um panorama dessas produções, muito embora não se constituam propriamente um estudo tipo "estado da arte". Dentre estes, Marques e Machado (2014) discutem a relação entre DS/SA e QV a partir da análise de artigos e livros internacionais. Sousa-Aguiar e colaboradores (2014) fornecem uma análise da produção bibliográfica mundial em QV. Mais recentemente o Green Chemistry Journal (Anastas et al., 2016) publicou números comemorativos dos 25 anos da QV onde, por meio de editais, ofereceu um panorama crítico da sua evolução e apontando desafios.

No Brasil, a difusão dos conceitos da QV no meio acadêmico, industrial e governamental vem crescendo (Sousa-Aguiar et al., 2014). Um interessante levantamento sobre publicações de índole educacional, envolvendo os temas do DS, QV e Educação Ambiental (EA), em veículos de divulgação da SBQ, entre 2002 a 2014, indicam o crescente interesse sobre a temática da QV e suas relações com o DS (Zuin et al., 2015). Segundo os autores, as "discussões sobre os impactos socioambientais do desenvolvimento científico têm se mostrado oportunas no ensino da QV" (p.87). Uma das autoras, em outro trabalho, aponta, assertivamente, que o avanço tecnocientífico também pode contribuir para a manutenção da vida e diminuição dos problemas, embora com necessário comprometimento e criticidade, a fim de ampliar a visão socioambiental e da sustentabilidade (Zuin, 2013). Nesse âmbito do ensino, a pesquisa de Costa e colaboradores (2008) efetuou uma análise sistemática na literatura em artigos que tratam do ensino da QV, principalmente no Journal of Chemical Education, entre 1996 e 2007. No estudo original, de uma tese de doutorado (Costa, 2011), a pesquisa buscou pelo termo Green Chemistry e os artigos selecionados foram classificados como: divulgação, ensino, experiências de demonstração e de laboratório, métricas e resenhas em geral. Os autores deram especial importância a práticas experimentais da QV, pois pretendiam aferir a extensão da penetração desta nova atitude de realização da química no ensino secundário português.

São vários os estudos que buscam compreender e defender a QV como um novo modo de pensar e praticar a química mais ligada a SA (Marques; Machado, 2014), defendendo que a QV deva estar mais presente no ensino da Química (Roloff, 2011; Góes et al., 2013; Marques et al., 2013; Sandri; Santin-Filho, 2016). Ainda que hajam avanços, a circulação de suas produções e incorporação no ensino parecem se dar mais em nível superior (Haack, 2016), corroborando com algumas pesquisas que têm apontado a existência de dificuldades na formação adequada em temas que a QV desenvolve (Correa; Zuin; 2009; Marques et al., 2013), maiormente ao ensino secundário (Costa, 2011; Zuin; Marques, 2014). 


\section{A importância da circulação de conhecimentos e práticas QV à evolução da química}

As formas de se resolver um determinado problema estão ligadas a "percepção direcionada em conjunção com o processamento correspondente no plano mental e objetivo" (Fleck, 2010, p. 149), portanto, ligada ao EP de um ou mais indivíduos. No caso da $\mathrm{QV}$, as questões que a desencadearam se encontravam inseridas no contexto histórico americano marcado sócio e ambientalmente por controvérsias, particularmente de movimentos sociais que exigiam soluções aos problemas da poluição, cuja resposta inicial foi o Pollution Prevetion. Os anos seguintes, depois do lançamento dos 12 Princípios da QV (Anastas; Warner, 1998), suas ideias e resultados foram difundidos mundialmente, em um processo de extensão de suas produções científicas tanto entre os chamados químicos verdes, quanto nas diferentes áreas da Química, portanto em círculos distintos - de especialistas ou não especialistas em QV (ou, em círculos esotéricos e exotéricos, respectivamente) (Fleck, 2010). De modo genérico, tal estratificação pode expressar uma maneira singular de ver o objeto do conhecimento e de se relacionar com ele, exprimindo um determinado EP. O círculo esotérico é formado por um coletivo de indivíduos especialistas. Enquanto que o círculo exotérico é constituído pelos leigos formados (ou não) que se relacionam com o mesmo EP, do saber produzido pelos sujeitos do círculo esotérico. A dinâmica envolvida no tráfego de conhecimento entre estes círculos é chamada de circulação intercoletiva e intracoletiva de ideias (Fleck, 2010). A primeira ocorre dentro do círculo esotérico, ou seja, entre pares; enquanto a circulação intercoletiva torna-se responsável "pela disseminação, popularização e vulgarização EPs para outros coletivos de não especialistas" (Delizoicov, 2004, p. 166). Contudo, os sujeitos podem pertencer simultaneamente a distintos coletivos, atuando como transmissores de ideias entre os coletivos de pensamento (CP). Logo, acompanhar e compreender o processo de circulação de ideias e práticas ajuda a identificar interlocuções teóricas ligadas a QV e, eventualmente, ao seu ensino. É uma espécie de resgate de uma identidade em formação, envolve uma dimensão social e um trabalho coletivo, constituintes de aspectos epistemológicos valiosos para se interpretar a sociogênese do conhecimento.

\section{Aspectos metodológicos}

Para esta investigação, a seleção e analise de trabalhos se deu a partir de publicações SBQ no período entre 2002 e 2014³ , e compreendeu os Anais de suas Reuniões Anuais (RASBQ) e os periódicos: Química Nova (QN), Química Nova na Escola (QNEsc), Revista Virtual de Química (RVq) e Journal of the Brazilian Chemical Society (JBCS). As buscas ocorreram diretamente na plataforma virtual PubliSBQ, por meio da identificação das palavras-chave: QV, Ensino de/da QV, Green Chemistry (GC), GC Education e GC Teaching. A escolha da SBQ se deu por ser esta a principal sociedade de Química do país, aglutina parcela significativa da comunidade acadêmica da química, destacando-se na divulgação de

\footnotetext{
${ }^{3}$ Esta pesquisa deriva de uma tese de doutorado (Roloff, 2016) e o período escolhido representa o início de publicações acerca da QV e a crescente presença desta nos eventos e meios de divulgação da SBQ.
} 
trabalhos voltados à QV e também à Sustentabilidade, a SA e ao DS, com ligação ao ensino da química e da QV (Zuin; Marques, 2014). A Tabela 1 reporta esse levantamento, bem como a respectiva distribuição dos trabalhos, em cada um dos veículos pesquisados.

Tabela 1: Número de publicações QV anuais da SBQ (2002 - 2014).

\begin{tabular}{|c|c|c|c|c|c|}
\hline ANO & RVq & JBCS & QN & QNEsC & RASBQ \\
\hline 2002 & --- & 1 & 1 & --- & 1 \\
\hline 2003 & --- & 1 & 3 & 1 & 4 \\
\hline 2004 & --- & 1 & --- & --- & 5 \\
\hline 2005 & --- & 1 & 2 & --- & 5 \\
\hline 2006 & --- & 2 & --- & --- & 4 \\
\hline 2007 & --- & 2 & 3 & 1 & 4 \\
\hline 2008 & ---- & 2 & 2 & 1 & 11 \\
\hline 2009 & --- & 1 & 3 & 1 & 6 \\
\hline 2010 & 3 & 2 & 3 & --- & 7 \\
\hline 2011 & 3 & --- & 2 & --- & 17 \\
\hline 2012 & 3 & 2 & 8 & --- & 8 \\
\hline 2013 & 2 & 3 & 2 & --- & 11 \\
\hline 2014 & 10 & 4 & 9 & --- & $23^{*}$ \\
\hline TOTAL & 23 & 22 & 38 & 4 & 106 \\
\hline
\end{tabular}

Nota: *Esta foi a primeira reunião que contou com uma seção exclusiva para trabalhos em

QV. (Roloff, 2016)

Desse levantamento percebe-se o crescimento de publicações em QV ao longo do tempo, principalmente nas RASBQ, embora os periódicos QN e RVq demonstrem evolução maior no número de publicações a partir de 2012. Não obstante, desde 2002 o JBCS, a QN e as RASBQ já publicassem trabalhos com os termos QV e/ou GC.

De posse do material, com um corpus de análise representado por 193 produções, passamos a construir a sua distribuição (Tabela 2), considerando o respectivo foco e veículo em que foi divulgado.

Tabela 2: Síntese da distribuição das produções QV na SBQ (2002 - 2014).

\begin{tabular}{|c|c|c|c|c|c|c|c|c|c|c|c|c|c|}
\hline \multirow{3}{*}{ 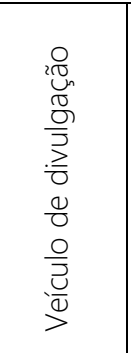 } & \multirow{3}{*}{ 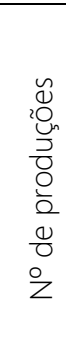 } & \multicolumn{12}{|c|}{ FOCO } \\
\hline & & \multicolumn{10}{|c|}{ Conteúdos disciplinares } & \multicolumn{2}{|c|}{$\begin{array}{c}\text { Currículo } \\
\text { (Formação e ensino) }\end{array}$} \\
\hline & & $\begin{array}{l}\text { U) } \\
\text { ơ }\end{array}$ & $\stackrel{\wp}{\underline{z}}$ & 迆 & $\sum_{<}^{\nwarrow}$ & $\sum_{<}^{\infty}$ & 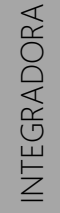 & 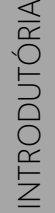 & $\begin{array}{l}\frac{a}{x} \\
u \\
\tilde{u} \\
\bar{u}\end{array}$ & $\frac{\curvearrowleft}{\square}$ & $\sum_{0}^{\llcorner}$ & 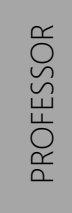 & 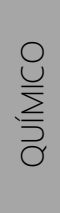 \\
\hline $\mathrm{R} \vee \mathrm{q}$ & 23 & 17 & - & 04 & - & - & - & - & - & 01 & - & 01 & - \\
\hline JBCS & 22 & 10 & - & 07 & 04 & - & - & - & - & 01 & - & - & - \\
\hline QN & 38 & 10 & 01 & 05 & 08 & 01 & - & - & - & - & - & 03 & 10 \\
\hline QNESC & 04 & - & - & - & - & - & - & - & - & - & - & 03 & 01 \\
\hline RASBQ & 106 & 50 & 01 & 16 & 17 & 02 & 03 & 03 & 01 & 01 & 01 & - & 11 \\
\hline Total & 193 & 87 & 02 & 32 & 29 & 03 & 03 & 03 & 01 & 03 & 01 & 07 & 22 \\
\hline
\end{tabular}

Nota: AMB (Química Ambiental); ANA (Química Analítica); CAT (Catálise); FIS (Físico-Química); QMT

(Química dos Materiais); INO (Química Inorgânica); ORG (Química Orgânica). (Zuin et al., 2015) 
O número de produções dirigidas ou tendo foco no ensino da QV , coluna currículo, é relativamente pequeno: $15 \%$ do total de produções. Observa-se ainda um grande número de trabalhos nas áreas da Orgânica, Analítica e Catálise (cerca de 77\%), o que não se diferencia do já evidenciado na literatura internacional, particularmente na Orgânica (Correa et al., 2013; Marques et al., 2013). Ainda foi possível evidenciar a quantidade significativa de trabalhos nas RASBQ (cerca de 55\%), talvez por ser este um espaço privilegiado de comunicações e de divulgação, especialmente para os jovens em fase de iniciação científica. Apesar de que nesse espaço os trabalhos apresentados sejam em formato de resumos (uma página), isso não criou maiores dificuldades na análise de conteúdo.

Como nos interessava análise específica daqueles textos que tratavam explicitamente do ensino da QV, nos debruçamos somente sobre os 29 trabalhos cujo foco era o currículo (Tabela 2). A partir da leitura na íntegra, destes trabalhos, realizamos uma classificação inicial considerando o tipo/característica do problema que origem as publicações (constituindo-se em nossa categoria analítica e expressa por seis subcategorias: Curricular, Estratégias, Atividades laboratoriais, Vínculo com outros aspectos, Materiais para uso no ensino e outra característica. Para tanto nos referenciando em Marques e Machado (2017) e Roloff (2016), estabelecendo critérios e descritores semelhantes, sinteticamente expressos na Figura 1.

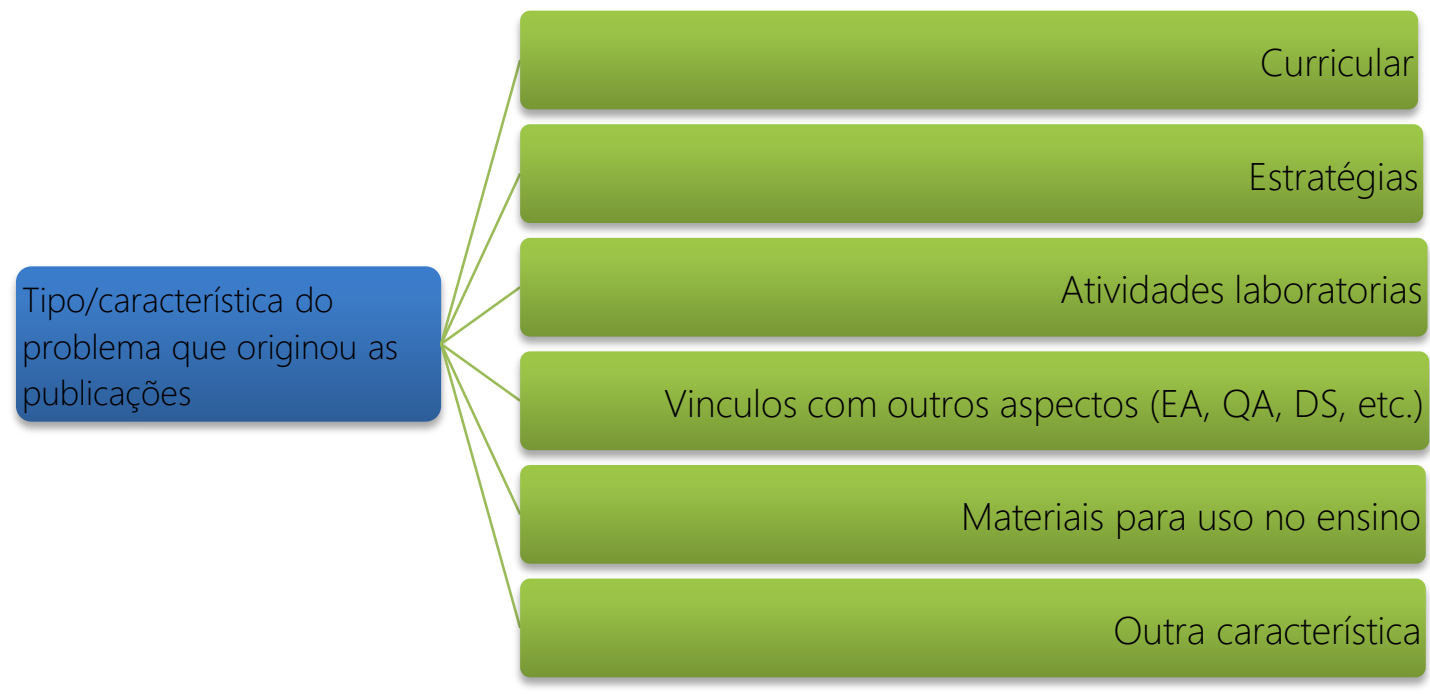

Figura 1: Categoria a priori e suas subcategorias analíticas: baseado em Marques e Machado (2017) e Roloff (2016)

O cenário classificatório é representado no Quadro 1, que traz maiores informações sobre os 29 trabalhos selecionados representando o círculo esotérico ${ }^{4}$.

\footnotetext{
${ }^{4}$ O número presente antes do título de cada trabalho visa simplificar a respectiva referência bibliográfica e as discussões posteriores.
} 
Quadro 1 - Círculo esotérico (trabalhos voltados ao ensino da QV): título do trabalho, veículo onde foi publicado e categoria

\begin{tabular}{|c|c|}
\hline \multirow{3}{*}{ 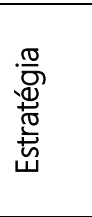 } & $\begin{array}{l}\text { (1) "Green Chemistry" - Os } 12 \text { Princípios da Química Verde e Sua Inserção nas Atividades de Ensino } \\
\text { e Pesquisa, QN, } 26 \text { (1), 123-129, } 2003 .\end{array}$ \\
\hline & (2) Desenvolvimento Sustentável e Química Verde QN, 28 (1), 103-110, 2005. \\
\hline & $\begin{array}{l}\text { (3) Química Verde e Formação de Profissionais do Campo da Química: Relato de uma Experiência } \\
\text { Didática para Além do Laboratório de Ensino, RVq, } 6 \text { (1), 73-84, } 2014 .\end{array}$ \\
\hline \multirow{5}{*}{$\frac{\frac{1}{2}}{\frac{\cos }{2}}$} & (4) Química Verde, os Desafios da Química do Novo Milênio, QN, 26 (5), 738-744, 2003. \\
\hline & $\begin{array}{l}\text { (5) O Conhecimento Químico e a Questão Ambiental na Formação Docente, QNEsc, 29, 30-33, } \\
\text { 2008. }\end{array}$ \\
\hline & (6) Recursos Humanos para Novos Cenários, QN, 32 (3), 567-570, 2009. \\
\hline & (7) Construindo Bases Teóricas para uma Educação Química Verde, $37^{\text {a }}$ RASBQ. \\
\hline & $\begin{array}{l}\text { (8) Questões Ambientais na Voz dos Formadores de Professores de Química em Disciplinas de } \\
\text { Cunho Ambiental, QN, } 37 \text { (3), 549-555, } 2014 .\end{array}$ \\
\hline \multirow{5}{*}{ 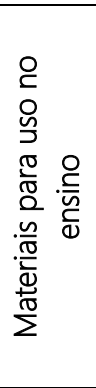 } & $\begin{array}{l}\text { (9) Uma Métrica Gráfica para Avaliação Holística da Verdura de Reações Laboratoriais - "Estrela } \\
\text { Verde", QN, } 33 \text { (3), 759-764, } 2010 .\end{array}$ \\
\hline & (10) Dos Primeiros aos Segundos Doze Princípios da Química Verde, QN, 35 (6), 1250-1259, 2012. \\
\hline & $\begin{array}{l}\text { (11) Novas Métricas Holísticas para Avaliação da Verdura de Reações de Síntese em Laboratório, } \\
\text { QN, } 35 \text { (9), 1879-1883, } 2012 .\end{array}$ \\
\hline & $\begin{array}{l}\text { (12) Análise da verdura química em atividades experimentais de disciplinas de graduação em } \\
\text { Química da UFSC, } 37^{\mathrm{a}} \mathrm{RASBQ} \text {. }\end{array}$ \\
\hline & $\begin{array}{l}\text { (13) Atualização da Estrela Verde para o sistema GHS: reconstruindo uma métrica ambiental } \\
\text { holística, } 37^{\mathrm{a}} \text { RASBQ. }\end{array}$ \\
\hline \multirow{4}{*}{$\begin{array}{l}\bar{\sigma} \\
\frac{0}{0} \\
\frac{0}{0} \\
\overline{0} \\
\frac{0}{0} \\
\frac{0}{0} \\
\frac{0}{0} \\
\frac{\pi}{0} \\
. \frac{1}{4}\end{array}$} & $\begin{array}{l}\text { (14) Síntese e Hidrólise de Azalactonas de Erlenmeyer-Plöchl Mediadas por Radiação Micro-Ondas } \\
\text { em Aparelhos Doméstico e Dedicado: Experimentos de Química Orgânica para a Graduação, QN, } 36 \\
\text { (1), 190-194, } 2013 .\end{array}$ \\
\hline & $\begin{array}{l}\text { (15) Vegetais como Reagentes Químicos: Uma Proposta Experimental Baseada na Química Verde, } \\
32^{\text {a }} \text { RASBQ. }\end{array}$ \\
\hline & (16) Propostas de Química Experimental Baseadas na Química Verde, 35ª RASBQ. \\
\hline & $\begin{array}{l}\text { (17) Resolução enzimática empregando-se cenoura: uma proposta de experimento para disciplina } \\
\text { de Química Orgânica Verde, } 35^{\mathrm{a}} \mathrm{RASBQ} \text {. }\end{array}$ \\
\hline \multirow{12}{*}{ 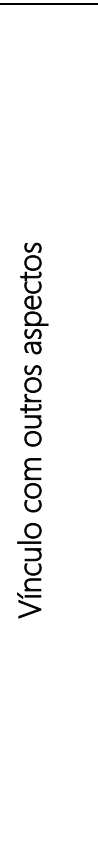 } & (18) Química a Serviço da Humanidade, QNEsc, Caderno Temático 5, 3-6, 2001. Vínculo: DS, SA, QA \\
\hline & $\begin{array}{l}\text { (19) Visões de Meio Ambiente e suas Implicações Pedagógicas no Ensino de Química na Escola } \\
\text { Média, QN, } 30 \text { (8), 2043-2052, 2007. Vínculo: DS, SA, Química Sustentável, EA }\end{array}$ \\
\hline & $\begin{array}{l}\text { (20) A Chuva Ácida na Perspectiva de Tema Social: Um Estudo com Professores de Química, QNEsc, } \\
\text { 25, 14-19, 2007. Vínculo: Temas sociais, Problematização, Contextualização }\end{array}$ \\
\hline & $\begin{array}{l}\text { (21) As representações sociais de Química Ambiental dos alunos iniciantes na graduação em } \\
\text { Química, QNEsc, } 31 \text { (1), 46-54, 2009. Vínculo: DS, Sustentabilidade, EA, QA }\end{array}$ \\
\hline & (22) Da Gênese ao Ensino da Química Verde, QN, 34 (3), 535-543, 2011. Vínculo: DS, Sustentabilidade \\
\hline & $\begin{array}{l}\text { (23) Vinte Anos de Química Verde: Conquistas e Desafios, QN, } 34 \text { (6), 1089-1093, 2011. Vínculo: DS, } \\
\text { Sustentabilidade }\end{array}$ \\
\hline & $\begin{array}{l}\text { (24) Sustentabilidade Ambiental: Um Estudo com Pesquisadores Químicos no Brasil, QN, } 36 \text { (6), 914- } \\
\text { 920, 2013. Vínculo: DS, SA, Sustentabilidade }\end{array}$ \\
\hline & (25) Um Projeto de Divulgação da Química Verde no Brasil, 30ª RASBQ. Vínculo: DS \\
\hline & $\begin{array}{l}\text { (26) Perspectivas da disciplina Introdução à Química Verde e Química Sustentável, } 32^{\text {a RASBQ. }} \\
\text { Vínculo: SA, Química Sustentável }\end{array}$ \\
\hline & $\begin{array}{l}\text { (27) Mapeamento do Entendimento de Conceitos de Química Verde nos Estratos Acadêmicos da } \\
\text { Universidade Federal do ABC, 34 }{ }^{\text {a }} \text { RASBQ. Vínculo: Sustentabilidade }\end{array}$ \\
\hline & (28) A Química Verde inserida nos experimentos didáticos de química, $35^{\text {a }}$ RASBQ. Vínculo: DS \\
\hline & $\begin{array}{l}\text { (29) Contribuições do ensino da Biotecnologia para a Química na Perspectiva da Química Verde, } 37^{\text {a }} \\
\text { RASBQ. Vínculo: Biotecnologia }\end{array}$ \\
\hline
\end{tabular}


Dessa organização metodológica, trazemos uma representação do cenário final encontrado.

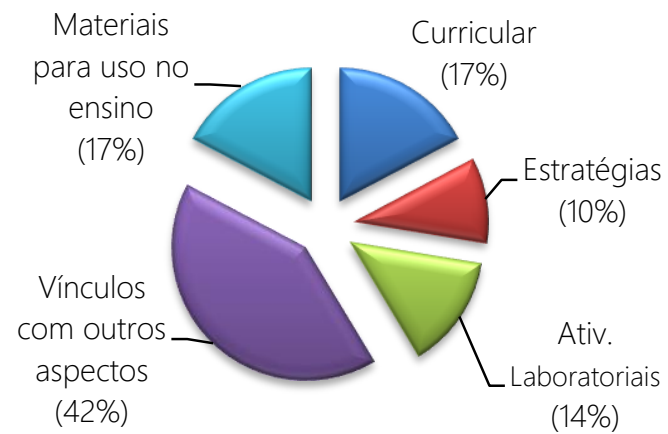

Gráfico 1: Tipo/característica do problema que originou as publicações, nos trabalhos voltados à formação do químico e de professores de Química (em \%)

Considerando o referencial teórico fleckiano e o objetivo de nossa pesquisa - levantar e discutir trabalhos voltados mais ao ensino da QV, assumimos para efeitos analíticos a constituição de dois tipos de círculos: o esotérico, formado por especialista no ensino da QV, cujos trabalhos (29) discutiam de forma mais explícita e substancial o papel e a aplicação da QV no ensino; e outro formando o círculo exotérico, constituído pelos demais trabalhos (164) produzidos por não especialistas em ensino, embora com relatos de experiências e sugestões ao emprego da QV.

Tal opção analítica não desconsidera, entretanto, que na formação inicial dos químicos, atuam tanto docentes das áreas específicas quanto àqueles de disciplinas mais ligadas ao campo da pedagógico (Gonçalves, 2009). Portanto, a ressonância de produções em QV oriunda desses dois círculos, atinge docentes que atuam nos cursos de licenciatura e de bacharelado, ainda que de distintos formas e percepções. A opção analítica considera ainda o fato de sujeitos poderem pertencer a dois círculos concomitantemente, promovendo interconexões que são facilitadas pela circulação de ideias e práticas (Fleck, 2010; Slongo; Delizoicov, 2010).

Dos trabalhos analisados, cinco dirigiam-se a questão curricular (4-8), três sobre estratégia de ensino (1-3) e outros doze pertenciam a subcategoria vínculos com outros aspectos (18-29). Cinco publicações vinculavam-se a subcategoria materiais para o ensino da QV (9-13), enquanto as outras quatro (14-17) apresentaram propostas voltadas às atividades laboratoriais.

Dentre os trabalhos categorizados como tendo Vínculo com outros aspectos, três argumentam sobre a importância do ensino da QV na reformatação da Química para o enfrentamento dos problemas ambientais, ligando tal objetivo ao alcance da Sustentabilidade e/ou ao DS. Dentre eles está o trabalho 22 que, ao tratar da gênese do conceito de QV, reconhece que essa teve origem no "âmbito de uma mudança de paradigma de gestão das medidas para proteção ambiental desenvolvidas pela indústria, da postura reativa para a preventiva" (p. 541), afirmando:

[o ensino da QV] deve hoje ser dirigido para o Desenvolvimento Sustentável, exigir uma visão ampla e holística da química, de natureza sistêmica, que possibilite a sua plena incorporação nos contextos ambiental, humano e societário [...] (p. 541). 
Outro é o trabalho 23, que trata da origem da QV comentando que essa tem se configurado numa mudança de mentalidade da prática Química por meio de temáticas específicas, e que os "progressos nessa área, portanto, podem ser o ponto chave nas conquistas de objetivos econômicos, como também um valioso avanço em direção a um desenvolvimento mais sustentável" (p. 1091). No trabalho 21, ao investigar representações sociais da Química Ambiental (QA) por alunos do curso de licenciatura em Química e do bacharelado em QA, assume que a QV é uma perspectiva melhor para explorar o tema da prevenção, distinguindo-se assim da Química do e no ambiente. Distinção essa já apontada na literatura (Machado, 2011; Leal, 2002).

Na subcategoria currículo, a pesquisa 5 analisa currículos de cursos de licenciatura em Química, argumentando sobre a QV dentro do quadro do DS e da Sustentabilidade. Para tanto, buscaram indícios do enfoque dado aos problemas ambientais em disciplinas dos cursos, salientando que nenhum desses cursos traziam conteúdos relacionados à QV, embora se defendesse a necessidade dessa no ensino da Química e na formação de seus professores. Argumentação semelhante é adotada no artigo 4, o qual discute a importância da QV como um novo conhecimento científico a ser inserido nos currículos e na prática científica, além de sua aplicação em escala comercial e industrial. $\bigcirc$ trabalho 8 analisa currículos de cursos de licenciatura em Química das regiões sul e sudeste do país, entrevistando professores responsáveis por disciplinas de cunho ambiental. Os autores destacam que a abordagem de questões ambientais nas disciplinas investigadas se dá por meio das perspectivas da EA, da QA e do enfoque CTS, apontam que em alguns casos essa abordagem ocorria também envolvendo exemplos e, especialmente, os princípios da QV.

Dentre os trabalhos que apresentam a QV como estratégia de ensino, destacamos o 3 que apresenta uma experiência voltada à educação em QV, dirigida à formação docente, a partir de uma proposta epistemológica e em consonância com pesquisas mais atuais da área da educação e do ensino de ciências, especialmente no que tange à experimentação. Reconhecem que "os cursos de graduação em Química do país, bacharelado e licenciatura plena, devem ser praticados de forma a fazer com que os estudantes desenvolvam uma visão integrada da Química, em que os princípios da QV estejam inseridos de maneira transversal no currículo" (p. 75-76). Embora destaquem a inserção da QV no currículo, procuram ainda compreender os alcances e limites que uma estratégia centrada na experimentação em QV exerce na formação inicial docente. Já no artigo 2, ao discutirem a inserção da QV em cursos de graduação, os autores apresentam princípios norteadores, fornecem exemplos e fazem apontamentos positivos sobre seu uso, defendendo-a como uma estratégia para o DS.

Quanto aos trabalhos categorizados como materiais para uso no ensino, serve como exemplo a proposta de um instrumento denominado Estrela Verde (EV), apresentada no artigo 9. Os autores descrevem esse instrumento (representação gráfica quantitativa e qualitativa que incorpora os princípios da QV envolvidos em uma atividade experimental) para o cálculo de métricas da verdura química de reações de sínteses. Além de ter uma dimensão prática muito útil na verificação das características ambientais dos processos químicos, é também um instrumento pedagógico ao ensino de Química em geral.

Outros quatro trabalhos (14, 15, 16 e 17) apresentam e discutem sobre atividades laboratoriais, associando-as aos princípios da QV. Parte desses trabalhos derivam ou foram apresentados nas RASBQ, como por exemplo, o 17, onde é descrito um experimento utilizando a cenoura como fonte renovável de matéria-prima. Segundo os autores ele 
"contempla perspectivas científicas e ambientais, através da abordagem de conceitos de QV, cromatografia e estereoquímica" (2012, p. 1). Na publicação 15, é apresentado um experimento em que a acetofenona foi reduzida por enzimas presentes na cenoura, pimentão verde e macaxeira, sendo uma alternativa ao método convencional que utiliza agentes redutores extremamente tóxicos. Os autores argumentam que é:

[...] um experimento viável, podendo ser aplicado em aulas práticas de química orgânica, sendo uma ferramenta pedagógica capaz de aplicar conceitos de química verde na intenção de formar profissionais aptos a compreender os novos conceitos científicos responsáveis pela sustentabilidade do planeta (p.1).

Já no trabalho 14, é reconhecido que o ensino experimental da QV tem assumido importante papel e apresentam a síntese de um heterociclo e sua reação de hidrólise. A execução do experimento proporciona discussões de métodos de síntese mais modernos utilizando os princípios da QV, os quais, segundo os autores, são importantes para a formação contemporânea dos profissionais de química.

Nos casos apenas citados, ainda que se justifique o uso da QV para o alcance do DS e da Sustentabilidade, as propostas tratam de experimentos em Química Orgânica, com variações técnicas sobre procedimentos de síntese (a exemplo do uso de matérias-primas renováveis). Nesse sentido, mantem-se presos a ideia de apontar ao currículo, exemplos para a melhoria na eficiência técnica visando a resolução de problemas ambientais; transparecendo estarem ainda presos à racionalidade instrumental (Chaui, 2010).

A análise permitiu argumentar que, ao longo do período investigado, diferentes características balizaram as produções em QV, as quais tem buscado contribuir, em diferentes formas e conteúdo, trazendo experiências e propostas ao seu ensino. Via a circulação dessas ideias o processo de formação é favorecido e novos conhecimentos (teóricos e práticos) podem ser disseminados pela atuação docente em sala de aula. A leitura dessas publicações pode auxiliar a instauração, extensão e até na transformação de EPs, no caso, evolvendo a crise ambiental e sua relação com a Química, por meio da adoção do princípio da prevenção e de cuidados com o ambiente. Uma mudança (evolução) - segundo Fleck (2010) - no EP de um sujeito está relacionada à circulação de ideias no âmbito intracoletivo de pensamento, "o que significa que pesquisadores de áreas afins estabelecem comunicação, resultando a 'importação' de novos conhecimentos e práticas que vão influenciar o modo de ver, de pensar e de agir em determinado campo do conhecimento" (Slongo; Delizoicov, 2010, p. 281).

Ao destacarmos a importância da circulação de ideias nesse campo novo de pesquisa denominado QV, por meio de resultados de pesquisa, experiências de ensino e textos para a sua disseminação, é possível inferir que está ocorrendo um processo de sociogênese de conhecimento, particularmente no campo do ensino e formação química. Tal interação entre os autores e formadores, pode instaurar processos de problematização tanto das produções dos autodenominados químicos verdes quanto das propostas de ensino da QV. Algumas características que nos ajudam a compreender o compartilhamento de ideias puderam ser extraídas dos 29 trabalhos publicados no âmbito da SBQ: cinco têm origem em dissertações (3, 5, 8, 20 e 21), outros doze trazem como autor ou coautor um pesquisador que publica em QV (Marques: 7, 12, 13, 19, 24 e 29); Andrade (em 6 e 18); Silva e Jones Jr. (em 2); Lenardão (em 1); Bazito (em 25) e Prado (em 4). Outras 4 publicações (todas no periódico QN) são de autoria (ou coautoria) do professor Machado (em 9, 10, 11 e 
22). Percebemos ainda que tanto trabalhos apresentados na RASBQ (na $32^{a}$, $34^{a}$ e $35^{a}$ edições, respectivamente os trabalhos 15, 16, 17, 26 e 27), quanto em uma publicação (em 9) na QN, em 2013, houve a colaboração de autoria, ou seja, trabalhos distintos envolvendo as mesmas pessoas.

A análise dos conteúdos das produções selecionadas em seus problemas e tipo de pesquisa (relatos de experiência, visões de sujeitos e/ou formulação de propostas), os referenciais teóricos utilizados e os procedimentos metodológicos adotados, está indicando reverberações na formação dos químicos e dos professores de Química. Todavia, várias propostas de ensino da QV ainda se caracterizaram por ser de inserção de pontual de atividades dentro ou durante a abordagem de conteúdos programáticos tradicionais, ou de oferecimento de uma disciplina específica de QV. Para ter um efeito sinérgico de mudança no EP dos químicos em relação aos cuidados com o ambiente, entendemos que a QV, seus domínios, procedimentos e princípios, precisam ser introduzidos transversalmente em todas as áreas da Química, permitindo a incorporação de soluções às situações/complicações sócio-científicas próprias dos desafios de uma Química voltada a prevenção de problemas ambientais.

\section{Considerações finais}

O levantamento e as discussões possibilitaram compreender a importância da circulação de conhecimentos e práticas acerca da QV em publicações da SBQ, bem como diferentes motivações e problemas que levaram os seus autores a produzirem nessa perspectiva, especialmente aquelas que promoveram reflexões e proposições de cunho educacional. A maioria desses trabalhos mostra enfoques envolvendo interações entre os sistemas social (educacional e político) e o natural. Mas também se percebeu que a natureza de algumas proposições denota preocupações mais técnicas como o fazer químico. Tal variedade de proposições, modelos e sugestões para o trabalho com a QV, promovem modos de se ensinar a química "mais verde" e também um indicativo de que a circulação de ideias pode estar favorecendo processos formativos. Mas, percebeu-se uma estreita relação de "dependência" entre o círculo de especialistas em ensino da QV (esotérico) e às produções derivadas de pesquisas em QV, o que, em sentido fleckiano, denota ser este círculo dependente do segundo círculo, formado pelos autodenominados químicos verdes, ainda que ambos estejam instaurando o CP em QV. Em âmbito mais abrangente, o aumento de interesse, proposições e experiências ancorados nos princípios da QV permite concluir que há evidências quanto a alteração no modo de pensar a Química, mas cujo grau ou nível de evolução ainda precisa ser melhor avaliado.

\section{Agradecimentos}

Ao CNPq, Projeto Universal n 481289/2012-7

\section{Referências}

ANASTAS, P. T.; WARNER, J. C. Green Chemistry - Theory and Practice. New York: Oxford University Press, 1998. 
ANASTAS, P. T. et al. Happy silver anniversary: Green Chemistry at 25. Green Chem. J., v.18, p. 12-13, 2016.

BARBOSA, L. C. A.; et al. A. O Princípio da Precaução no Ensino de Ciências como possibilidade para a promoção de discussões Sociocientíficas. IENCI, v.21, p. 137-152, 2016. BROWNER, C. M. Pollution Prevetions Takes Center Stage. EPA Journal, v.19, n.3, p. 6-8, 1993.

CHAUI, M. S. Convite à Filosofia. São Paulo: Editora Ática, 2010.

CMMA. Comissão Mundial sobre Meio Ambiente e Desenvolvimento, Nosso Futuro

Comum. 2ed. Rio de Janeiro: Fundação Getúlio Vargas, 1991. 430 p.

CORRÊA, A. G.; ZUIN, V. Química Verde: fundamentos e aplicações. São Carlos: EdUFSCar, 2009.

CORRÊA, A. G. et al. Green chemistry in Brazil. Pure Appl. Chem., v.85, n.8, p. 1643-1653, 2013.

COSTA, D. A.; et al. Uma revisão da bibliografia sobre o ensino da Química Verde. Boletim da SPQ, n.109, p. 47-51, 2008.

COSTA, D. A. Métricas de Avaliação da Química Verde - Aplicação no Ensino Secundário. Doutorado em Ensino e Divulgação das Ciências. U. Porto, Porto, 2011.

DELIZOICOV, D. Pesquisa em Ensino de Ciências como Ciências Humanas Aplicadas.

Caderno Brasileiro de Ensino de Física, v.21, p. 145-175, 2004.

EPICOCO, M. et al. Knowledge dynamics and sources of eco-innovation: Mapping the Green Chemistry community. Technological Forecasting \& Social Change, v.81, p. 388-402, 2014

FLECK, L. Gênese e desenvolvimento de um fato científico. Belo Horizonte: Fabrefactum, 2010.

GEORGESCU-ROEGEN, N. O decrescimento: entropia, ecologia, economia. São Paulo: Editora Senac, 2012.

GRAEDEL, T. E.; ALLENBY, B. R. Industrial Ecology. New York: Prentice Hall, 1995.

GOES, L. F. et al. Aspectos do Conhecimento pedagógico do Conteúdo de Química Verde em professores Universitários de Química. Educación Química, v.24, n.1, p. 113-123, 2013

GONÇALVES, F. P. A problematização das atividades experimentais no desenvolvimento profissional e na docência dos formadores de professores de Química. Doutorado em Educação Científica e Tecnológica. UFSC - Florianópolis. 2009.

HAACK, J. A.; HUTCHISON, J. E. Green Chemistry Education: 25 Years of Progress and 25 Years Ahead. ACS Sustainable Chem. Eng. v.4, n.11, p. 5889-5896, 2016.

INTERGOVERNMENTAL PANEL ON CLIMATE CHANGE. Emissions Scenarios: a special report of IPCC Working Group III (SRES). Cambridge: Cambridge: University Press, 2000.

LEAL, A. L. A articulação do conhecimento químico com a problemática ambiental na formação inicial de professores. Mestrado em Educação. UFSC - Florianópolis, 2002.

MACHADO, A. A. S. C. Da Gênese ao Ensino da Química Verde. Quím. Nova, v. 34, n. 3, p. 535-543, 2011. 
MARION, P. et al. Perpective_Sustainable chemistry: how to produce better and more from less. Green Chem. J., september 2017.

MARQUES, C. A.; MACHADO, A. A. S. C. Environmental sustainability: implications and limitations to green chemistry. Foundations of Chemistry, v.16, n.2, p. 125-147, 2014.

MARQUES, Carlos; MACHADO, Adélio. Una visión sobre propuestas de enseñanza de la Química Verde. Revista Electrónica de Enseñanza de las Ciencias, v. 17, n. 1, 2018.

MOZETO, A. A.; JARDIM, W. F. A Química Ambiental no Brasil. Quím. Nova, v.25, supl., p. 7$11,2002$.

NASCIMENTO, E. P do. Sustentabilidade: o campo de disputa de nosso futuro civilizacional. In: LÉNA, P.; NASCIMENTO, E. P. (Orgs.). Enfrentando os limites do crescimento: sustentabilidade, decrescimento e prosperidade. Rio de Janeiro: Garamond, 2012.

REES, W. E. Ecological footprints and appropriated carrying capacity: what urban economics leaves out. Environment and Urbanisation. v.4, n.2, p. 121-130, 1992.

RITTER, S. K. Green Chemistry. Chemical and Engineering News, v.79, n.29, p. 24- 34, 2001.

ROLOFF, F. B. Questões Ambientais em Cursos de Licenciatura em Química: as vozes do currículo e professores. Mestrado em Educação Científica e Tecnológica. UFSC -

Florianópolis. 2011.

ROLOFF, F. B. A Circulação de Conhecimentos em Química Verde em Teses e Dissertações: Implicações ao seu Ensino e à Formação de Professores de Química. Doutorado em Educação Científica e Tecnológica. UFSC - Florianópolis. 2016.

SANDRI, M. C. M.; SANTIN FILHO, O. Implicações da Inserção da Química Verde na Formação Inicial de Professores de Química. ReBEQ, v.11, n.1, p. 111 - 124, 2016.

SCOTT, J. L.; LEE, J. Appropriate lifetimes, fitting deaths. Green Chem. J., v.18, p. 6157-6159, 2016.

SLONGO, I. I. P.; DELIZOICOV, D. Teses e Dissertações em Ensino de Biologia: Uma Análise Histórico- Epistemológica. IENCl, v.1, n.2, p. 275-296, 2010.

SOUSA-AGUIAR, E. F. et al. Química Verde: a Evolução de um Conceito. Quím. Nova, v.37, n.7, p. 1257-1261, 2014.

WCED (World Commission on Environmental and Development). Our common future. Oxford: Oxford University Press, 1987.

ZUIN, V. G. A inserção da Química Verde nos programas de pós-graduação em Química do Brasil: tendências e perspectivas. RBPG, v. 10, n. 21, p. 557-573, 2013.

ZUIN, V. G.; MARQUES, C. A. Sustainable Development, Green Chemistry and Environmental Education in Brazil. In: EILKS, S. MARKIC, E.S.; B. RALLE, SHARKER, B. R. (Orgs.). Science education research and education for sustainable development (EDS): Aachen, 2014, v.1, p. 147-156.

ZUIN, V. G. et al. Desenvolvimento Sustentável, Química Verde e Educação Ambiental: o que revelam as publicações da SBQ. ReBEQ, v.10, p. 79-90, 2015. 